annual screening for advisory leads, (2) if loss of capture is detected, even though all cases were due to lead displacement, it will allow for better planning in cases where the lead is perforated through a chamber. As there is poor correlation for the rest of the indications it might be worth conducting larger review of practices to establish whether the yield from routine screening is useful. Our institution will review practices over last 5 years subsequent to this finding.

\section{THE PREVALENCE OF SLEEP DISORDERED BREATHING IN ELDERLY PATIENTS WITH PERSISTENT ATRIAL FIBRILLATION}

William Eysenck*, Neil Sulke, Steve Furniss, Rick Veasey. Cardiology Research Department, Eastbourne Hospital, East Sussex Healthcare NHS Trust

\subsection{6/heartjnl-2017-311726.39}

Introduction Epidemiological data have demonstrated an independent association between sleep-disordered breathing (SDB) and atrial fibrillation (AF). We have developed an efficient and reliable screening service investigating SDB in patients (pts) $>65$ years with persistent AF. Polysomnography (PSG) in a sleep laboratory (lab) is the gold standard diagnostic tool but expense and waiting lists for sleep centres have resulted in a search for alternative methods. The Watch PAT (WP) is

\begin{tabular}{|c|c|}
\hline Variable Tested & Mean ( \pm SD) \\
\hline Neck circumference $(\mathrm{cm})$ & $41.85( \pm 5.829)$ \\
\hline BMI (kg/m2) & $30.8( \pm 7.077)$ \\
\hline Epworth score & $8.54( \pm 4.502)$ \\
\hline Mean sleep time (hours) & $6.9017( \pm 1.835)$ \\
\hline \%REM & $19.824( \pm 8.84)$ \\
\hline Respiratory Disturbance Index & $27.90( \pm 18.39)$ \\
\hline Apnoea-Hypopnoea Index (AHI) & $24.11( \pm 19.9)$ \\
\hline Oxygen Desaturation Index & $17.427( \pm 17.77)$ \\
\hline Mean Respiratory Event & $171.89( \pm 114)$ \\
\hline Resp Event (AHI) & $146.17( \pm 121)$ \\
\hline Desaturations & $104.22( \pm 104.77)$ \\
\hline Mean snoring intensity (dB) & $40.9( \pm 2.4)$ \\
\hline $\begin{array}{l}\text { Mean Cost: } \\
\text { WatchPAT } \\
\text { Predictive cost PSG }\end{array}$ & $\begin{array}{l}£ 25.95( \pm 4.8)^{*} \\
£ 301.45( \pm 78.4)\end{array}$ \\
\hline
\end{tabular}

${ }^{*}$ Mean cost of WP is less than corresponding predictive cost of PSG $(P<0.0001)$ efficient and reliable with strong correlation to PSG, potentially negating the requirement for sleep lab investigation.

Methods 20 pts $>65$ years, mean age 71 (45\% male), with persistent AF awaiting treatment were investigated for SDB with WP. Total device expenditure including pt and technician cost were compared with predictive cost of PSG and sleep lab studies.

Results See table 1.

According to the UK NICE definition 18/20 (90\%) had evidence of SDB. $8 / 20(40 \%)$ could be considered to have severe sleep apnoea. The mean REM sleep percentage was $20.4 \%$ and mean snoring intensity was $40.9 \mathrm{~dB}$. WP cost was significantly less than predictive cost of PSG $(\mathrm{p}<0.0001)$. Conclusion: There is a high prevalence of SDB in older pts with $\mathrm{AF}$ and use of the WP as a screening option is feasible. The higher than average non-REM sleep and only mildly elevated snoring intensity implicates a central component in these pts related to cardiac co-morbidity. Further study is ongoing to assess AF therapy outcomes in such pts.

\section{RIGHT VENTRICULAR HIGH SEPTAL PACING VS. RIGHT VENTRICULAR APICAL PACING FOLLOWING AV NODE ABLATION: 20 YEARS FOLLOW UP}

William Eysenck*, Rick Veasey, Angela Gallagher, Fadi Jouhra, Nikhil Patel, Steve Furniss, Neil Sulke. Cardiology Research Department, Eastbourne Hospital, East Sussex Healthcare NHS Trust

\subsection{6/heartjnl-2017-311726.40}

Introduction Right ventricular septal (RVS) pacing is often recommended as a more physiological alternative to right ventricular apical (RVA) pacing. Most comparisons between the two sites have had short follow up and few trials have assessed the different pacing sites following atrioventricular node (AVN) ablation. We analysed 200 consecutive patients (pts) aged 66-96 (51\% male) who underwent implantation of a pacemaker prior to AVN ablation with either RVA- or RVSpacing between 1996 to 2016.

Methods All hospital notes were retrieved and reviewed. Radiographic data for the site of $\mathrm{V}$ lead, all hospitalisations, change in echocardiography ejection fraction (EF), QRS width trend and lead parameters were collated. All pts additionally underwent dyssynchrony echocardiography.

Results See tables 1 and 2 .

Conclusions (i) EF of less than 40\%; (ii) prior diagnosis of IHD and (iii) dilated cardiomyopathy independently predict HF admission following AVN ablation. However, there was no decrease in $\mathrm{EF}$ and no difference in inter-ventricular or intraventricular dyssynchrony with either pacing site after up to 20 year follow up. There was a decreased mortality rate with RVA pacing following AVN ablation after longterm follow up. We now prophylactically use CRT pacing in all pts with EF $40 \%$ and known IHD. Their outcome is part of ongoing follow up. 


\section{Abstracts}

Abstract 40 Table 1 Baseline characteristics

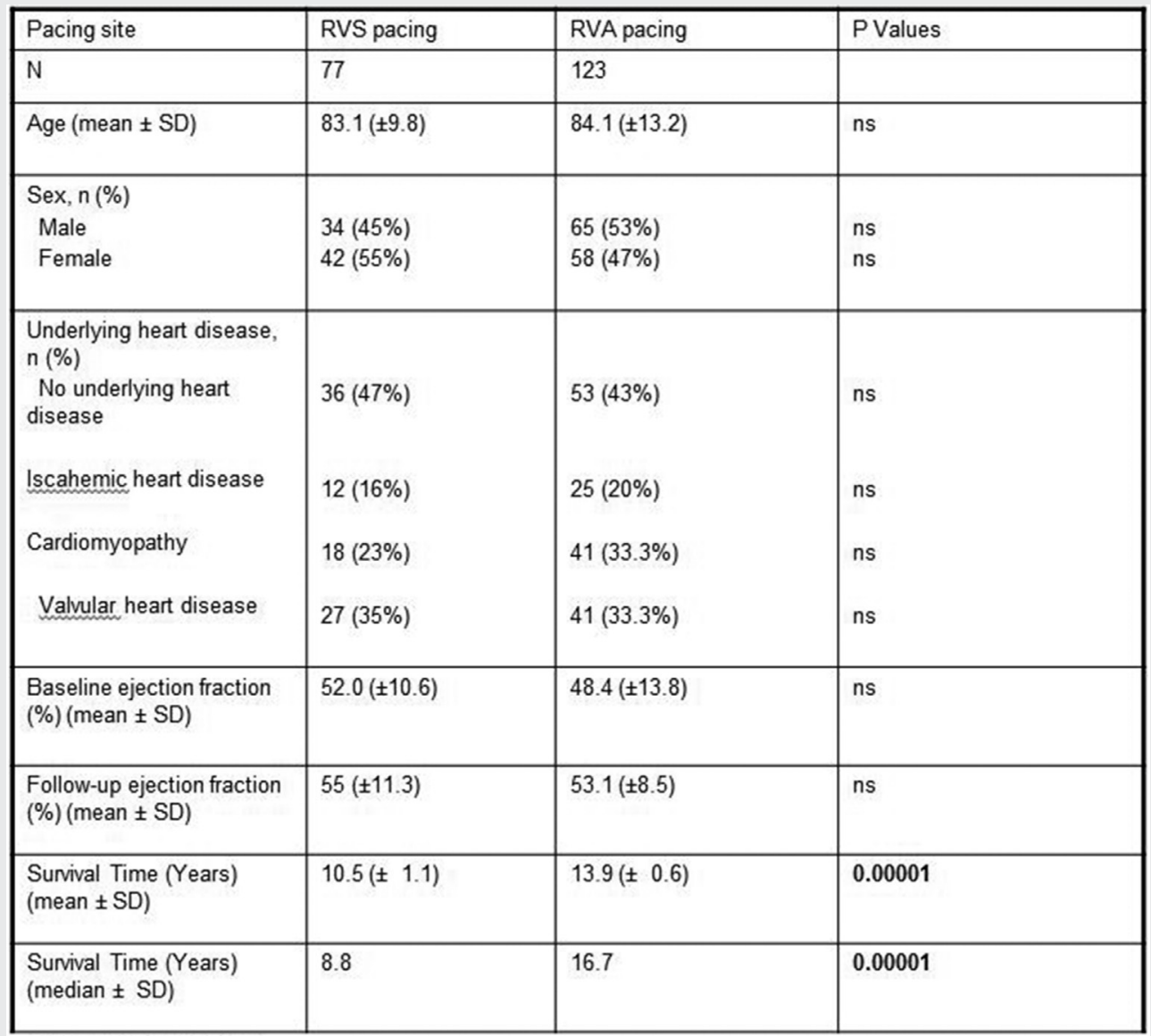

Abstract 40 Table 2 Patient characteristics with and without left ventricular decompensation

\begin{tabular}{|c|c|c|c|}
\hline & Developed CHF & No development of CHF & PValues \\
\hline $\mathrm{n}$ & 29 & 171 & ns \\
\hline Age (mean $\pm \mathrm{SD})$ & $79.4( \pm 7.9)$ & $77.7( \pm 6.4)$ & 0.8 \\
\hline $\begin{array}{l}\text { Gender, n (\%) } \\
\text { Male } \\
\text { Female }\end{array}$ & $\begin{array}{l}17(59 \%) \\
12(41 \%)\end{array}$ & $\begin{array}{l}80(48 \%) \\
87(52 \%)\end{array}$ & 0.1 \\
\hline $\begin{array}{c}\text { Disease } \\
\text { IHD }\end{array}$ & $19(67 \%)$ & $19(11.5 \%)$ & 0,0001 \\
\hline $\begin{array}{l}\text { Dilated } \\
\text { Cardiomyopathy }\end{array}$ & $19(67 \%)$ & $36(21.8 \%)$ & 0.0001 \\
\hline Valvular heart disease & $13(44 \%)$ & $55(33 \%)$ & 0.5 \\
\hline $\begin{array}{l}\text { Ejection fraction (\%) prior to } \\
\text { AVN ablation }\end{array}$ & $39.3 \%$ & $52 \%$ & 0.01 \\
\hline QRS duration (mean $\pm \mathrm{SD}$ ) & & & \\
\hline $\begin{array}{l}\text { At baseline: } \\
\text { Following AVN } \\
\text { ablation: }\end{array}$ & 91 ( \pm 16.8); & $94.7( \pm 20.5)$ & ns \\
\hline $\begin{array}{l}0-40 \text { months } \\
40-80 \text { months } \\
80-120 \text { months }\end{array}$ & $\begin{array}{l}154.6( \pm 11.4) \\
159.3( \pm 13.3) \\
164.3( \pm 12.6)\end{array}$ & $\begin{array}{l}143.4( \pm 20.9) \\
163.0( \pm 49.6) \\
134.0( \pm 20.0)\end{array}$ & $\begin{array}{l}\text { ns } \\
\text { ns } \\
\text { ns }\end{array}$ \\
\hline
\end{tabular}

